\title{
Hiwi overexpression does not affect proliferation, migration or apoptosis of liver cancer cells in vitro or in vivo
}

\author{
HAO LI ${ }^{1}$, CHEN-XI SHI $^{1}$, HUI LIU ${ }^{1}$, HAI-HAN ZHANG ${ }^{2}$, HUAI-MING SANG ${ }^{2}$, \\ MUHAMMAD-DJALEEL SOYFOO ${ }^{2}$, JIU-LIANG CAO ${ }^{2}$, SHUN-FU XU ${ }^{2}$ and JIAN-XIA JIANG ${ }^{2}$ \\ ${ }^{1}$ Department of Pathophysiology, Nanjing Medical University, Nanjing, Jiangsu 211166; ${ }^{2}$ Department of Gastroenterology, \\ The First Affiliated Hospital of Nanjing Medical University, Nanjing, Jiangsu 210029, P.R. China
}

Received August 7, 2016; Accepted March 16, 2018

DOI: $10.3892 / \mathrm{ol} .2018 .8585$

\begin{abstract}
Piwi like RNA-mediated gene silencing 1 (Hiwi) is a human homolog of the Piwi gene family that has been reported to be upregulated in hepatocellular carcinoma (HCC). The present study aimed to investigate the role of Hiwi in the initiation and development of HCC in vitro and in vivo. Adenovirus-mediated Hiwi overexpression was established in primary murine hepatocytes and SMMC7721 HCC cells. Cell viability and proliferation were assessed using MTT and EdU assays, respectively. Cell migration was measured using a scratch migration assay. The cell cycle was assessed using flow cytometry, and the expression of genes associated with the epithelial mesenchymal transition (EMT) was assessed using reverse transcription-quantitative polymerase chain reaction. SMMC7721 cells that stably express Hiwi were also generated and injected subcutaneously into the nude mice, and tumor growth was examined. Recombinant adenovirus encoding green fluorescent protein or Hiwi was delivered by injection into the tail vein, and its effect on murine hepatocyte gene expression was studied. The present study revealed that the overexpression of Hiwi did not affect the proliferation or migration of liver cancer cells and failed to suppress perifosine- or doxorubicin-induced apoptosis in vitro. The tumors of mice that were injected with Hiwi-expressing SMMC7721 cells were not significantly larger compared with mice that were injected with control SMMC7721 cells. Hiwi overexpression did not noticeably alter the expression of genes involved in EMT, either in vitro or in vivo. The results of the present study indicate that although expression of Hiwi is associated
\end{abstract}

Correspondence to: Dr Jian-Xia Jiang, Department of Gastroenterology, The First Affiliated Hospital of Nanjing Medical University, 300 Guangzhou Road, Nanjing, Jiangsu 210029, P.R. China

E-mail: jjxcasey@aliyun.com

Abbreviation: RNAi, RNA interference

Key words: Hiwi, hepatocellular carcinoma, proliferation, apoptosis with HCC development and progression in the clinic, it does not act as an oncogene in liver cancer cells.

\section{Introduction}

The piwi like RNA-mediated gene silencing 1 (Hiwi) gene is a human homolog of the P-element Induced wimpy testis (Piwi) gene family, which is a class of genes required for stem cell self-renewal in a range of organisms, including jellyfish, Caenorhabditis elegans, Drosophila melanogaster, Danio rerio, Mus musculus and humans (1). Previously, overexpression of Hiwi was reported to be associated with poor prognosis in patients with various human malignant tumors, including seminomas (2), esophageal squamous cell carcinoma (3), adenocarcinoma of the pancreas (4), gastric adenocarcinoma (5), colorectal cancer (6), soft-tissue sarcoma (7) and endometrial carcinoma (8), indicating that it may represent a promising biomarker and a potential target for anticancer treatment.

The function of Hiwi in tumorigenesis is unclear. Upregulation of Hiwi has been demonstrated to promote tumor cell growth in breast (9), cervical (10), endometrial (8) and colorectal cancer (6), as well as in mesenchymal stem cells (11), while its downregulation has been noted to suppress the growth, invasion and migration of glioma (12), gastric (5) and lung cancer (13). These observations indicate that Hiwi may act as an oncogene during carcinogenesis. However, Sharma et al (14) reported that overexpression of Hiwi suppressed proliferation and induced apoptosis of the acute myeloid leukemia-derived cell line KG1. Overexpression of Hiwi was reported to inhibit the growth of chronic myeloid leukemia K562 cells and enhance their chemosensitivity to daunomycin (15). These findings indicate that the biological functions of Hiwi may vary between types of tumor, necessitating its role in each cancer to be studied individually.

Hepatocellular carcinoma (HCC) is one of the most common malignancies in China (16). Elevated levels of Hiwi mRNA and protein have previously been observed in $\mathrm{HCC}$, and that Hiwi expression is positively associated with tumor metastasis $(17,18)$. It has been demonstrated that downregulation of Hiwi using RNA interference (RNAi) significantly suppressed the proliferation and invasion of HCC cell lines $(18,19)$. However, whether Hiwi exerts a direct tumorigenic role in 
HCC remains unknown. In the present study, an adenovirus vector was used to overexpress Hiwi in liver cells in vitro and in vivo, and the effect of Hiwi on cell growth and migration was evaluated in hepatocellular carcinoma SMMC7721 cells, primary hepatocytes and xenografts. Additionally, the effect of Hiwi on hepatotoxicant-induced apoptosis was examined.

\section{Materials and methods}

Cell culture. The effect of Hiwi overexpression on cell growth was evaluated in SMMC7721 cells and primary mouse hepatocytes, since these cells were reported to express low levels of endogenous Hiwi protein (18). 293 cells were obtained from the American Type Culture Collection (Manassas, VA, USA). SMMC7721 cells were established in 1977 by the Second Military Medicine College (Shanghai, China). These cells were derived from the liver tissue of a 50-year-old male with a grade II-III (20) hepatocellular carcinoma. SMMC7721 cells are epithelial in morphology. The number of chromosomes varies between 44 and 107; 70\% of the cells have 54-58 chromosomes. The cells are tumorigenic in nude mice but with a low metastatic potential. SMMC7721 and 293 cells were maintained in Dulbecco's modified Eagle's medium (DMEM; Invitrogen; Thermo Fisher Scientific, Inc., Waltham, MA, USA) supplemented with $10 \%$ fetal bovine serum (FBS, Invitrogen; Thermo Fisher Scientific, Inc.) and penicillin/streptomycin.

Primary murine hepatocytes were isolated from male ICR mic ( $n=6$, six weeks old, mean average weight $25 \mathrm{~g}$, purchased from the experimental animal center of Nanjing medical University, Nanjing, China) by in situ liver perfusion with collagenase via the portal vein. Mice were allowed free access to drinking water and food at room temperature $\left(25^{\circ} \mathrm{C}\right)$ with an automatic $12 \mathrm{~h}$ light and $12 \mathrm{~h}$ dark cycle. Mice were anesthetized with pentobarbital sodium, and the livers were then perfused in situ with $45 \mathrm{ml}$ calcium-free buffer $(100 \mathrm{mM}$ HEPES buffer at pH 7.4, $50 \mathrm{mM}$ EGTA), followed by $8 \mathrm{ml}$ liver digest medium (100 mM HEPES buffer at $\mathrm{pH} 7.6$, with $0.5 \mathrm{mg} / \mathrm{ml}$ collagenase IV). Next, the liver was excised, minced and strained through a steel mesh. Hepatocytes were obtained by centrifugation 3 times at $50 \mathrm{x}$ g for $5 \mathrm{~min}$ at $4^{\circ} \mathrm{C}$ and washed twice with DMEM. The hepatocytes were cultured in DMEM supplemented with $10 \%$ FBS and penicillin/streptomycin for further experiments.

Cloning of human cDNA and construction of plasmids. Human Hiwi cDNA containing the full open reading frame was synthesized commercially (Shanghai GeneChem Co., Ltd., Shanghai, China). The human Hiwi cDNA was sub-cloned into the pcDNA3.1-myc vector, specifically into the myc epitope sequence with EcoRI and XhoI sites, which yielded the pcDNA3.1-myc-Hiwi plasmid (Fig. 1A). The following primers were used: Forward 5'-AAAAAGAATTCACTG GGAGAGCCCGAGCCAGAGCC-3'; and reverse, 5'-AAA AAACTCGAGTTAGAGGTAGTAAAGGCGGTTTG-3'. The length of the plasmid was confirmed by electrophoresis in $0.5 \mathrm{x}$ Tris-acetate EDTA buffer with a $1.5 \%$ agarose gel containing $0.1 \mu \mathrm{g} / \mathrm{ml}$ of ethidium bromide. The DNA bands were visualized and analyzed by Biosense $810 \mathrm{Gel}$ Electrophoresis Image analytic system (Beyotime Institute of Biotechnology, Haimen, China). The full Hiwi coding region was verified by sequencing (performed commercially by Generay Co., Ltd., Shanghai, China).

Plasmid transfection. The 293 cells and SMMC7721 cells were transfected with pcDNA3.1-myc-Hiwi using Lipofectamine ${ }^{\circledR}$ 2000 (Invitrogen; Thermo Fisher Scientific, Inc.) according to the manufacturer's instructions, and the controls were transfected with the control vector. Cells were used for subsequent experiments $48 \mathrm{~h}$ after transfection. For stable transfection, the cells were selected with G418 (400 $\mu \mathrm{g} / \mathrm{ml}$; Sigma-Aldrich; Merck KGaA, Darmstadt, Germany) for 2 weeks.

Construction of recombinant adenoviruses. Recombinant adenoviruses expressing Hiwi were constructed commercially using an AdEasy Adenoviral Vector system (Stratagene; Agilent Technologies, Inc., Santa Clara, CA, USA) and the pAdTrack cytomegalovirus vector (Shanghai GeneChem Co., Ltd.). To induce adenovirus-mediated overexpression in vitro, $24 \mathrm{~h}$ after plating, the cells were incubated at $37^{\circ} \mathrm{C}$ for $4 \mathrm{~h}$ with adenovirus at a multiplicity of infection of 10-20 pfu per cell. Next, the virus was removed, and the cells were cultured at $37^{\circ} \mathrm{C}$ for an additional $24-48 \mathrm{~h}$ in fresh DMEM supplemented with $10 \% \mathrm{FBS}$ and penicillin/streptomycin. Under these conditions, infection efficiency routinely exceeded $90 \%$.

Confirmation of Hiwi overexpression by western blotting. The cells were lysed with Radioimmunoprecipitation Assay buffer containing protease inhibitors (Roche Diagnostics, Basel, Switzerland) for $15 \mathrm{~min}$ on ice. Following centrifugation for $15 \mathrm{~min}$ at $20,000 \mathrm{xg}\left(4^{\circ} \mathrm{C}\right)$, the protein content of the samples was determined according to the Bradford method. The protein lysates (50 $\mu \mathrm{g}$ per lane) were analyzed by SDS-PAGE ( $8 \%$ gel) and transferred onto methanol-activated polyvinylidene fluoride membranes. Non-specific binding sites were blocked with $5 \%$ non-fat milk in Tris-buffered saline $/ 0.1 \%$ Tween 20 for $2 \mathrm{~h}$ at room temperature. The membranes were incubated overnight with primary antibodies as follows: Hiwi (cat. no. ab12337; 1:1,000; Abcam, Cambridge, UK) or myc (cat. no. MABE282; 1:2,000; Sigma-Aldrich; Merck KGaA). Subsequent to being washed three times, the membranes were blotted with corresponding horseradish peroxidase-conjugated secondary antibody (cat. no. A0208 or A0216; 1:1,000; Beyotime Institute of Biotechnology) for $1 \mathrm{~h}$ at room temperature. The membranes were rinsed three times and then developed with enhanced chemiluminescence reagent using the ECL chemiluminescence kit (Thermo Fisher Scientific, Inc.). The two primary antibodies detected proteins with a molecular mass of $\sim 98 \mathrm{kDa}$ (Fig. $1 \mathrm{~B}$ and $\mathrm{C}$ and data not shown), which is consistent with the reported molecular weight of human Hiwi (2). $\beta$-actin (cat. no. A5316; Sigma-Aldrich, USA) was used as the internal control.

Assessment of cell viability by MTT assay. An MTT assay was performed in 96 -well plates. Briefly, $1 \times 10^{4}$ primary mouse hepatocytes were seeded per well and cultured overnight prior to infection with the adenovirus. At $0,20,40,60,80 \mathrm{~h}, 10 \mu \mathrm{l}$ MTT ( $5 \mathrm{mg} / \mathrm{ml}$; Sigma-Aldrich, Merck KGaA) was added to each well, and after $4 \mathrm{~h}$ of incubation at $37^{\circ} \mathrm{C}$, the medium was gently decanted, and dimethysulfoxide (100 $\mu \mathrm{l} /$ well) was added to dissolve the formazan product. The absorbance at 
A

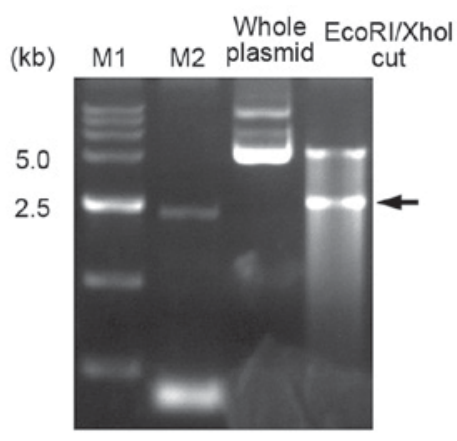

C

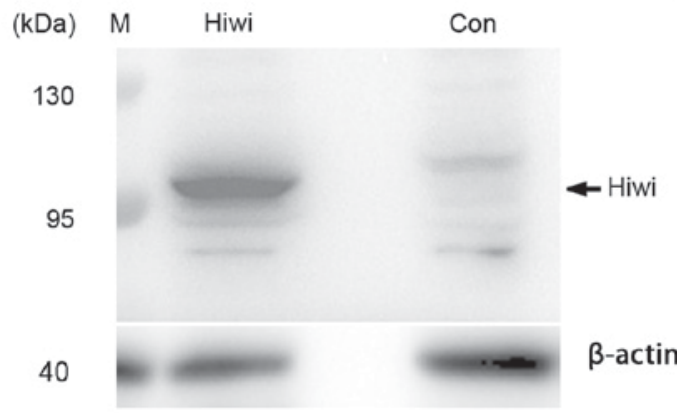

B

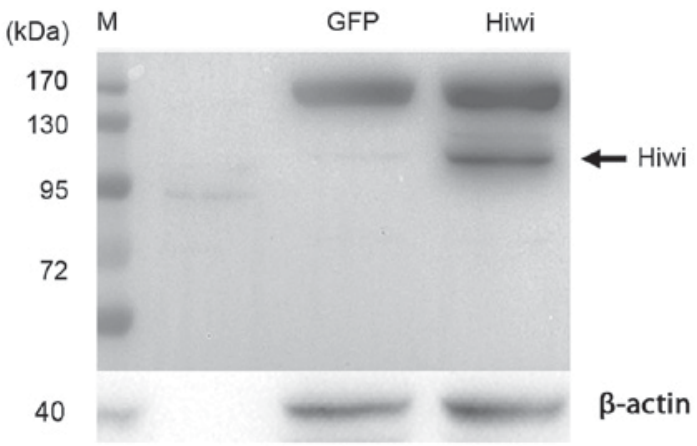

D

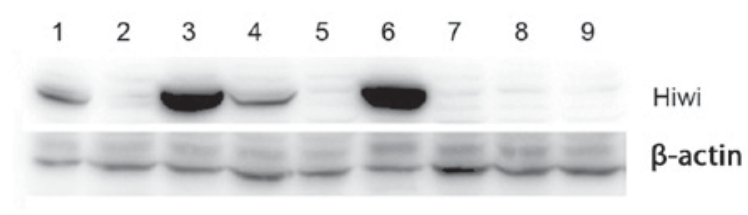

Figure 1. Generation of human Hiwi-expressing plasmid. (A) PcDNA3.1-myc-Hiwi plasmids were cut using EcoRI and XhoI restriction enzymes and separated by agarose gel electrophoresis. The arrow indicates inserts of $\sim 2.5 \mathrm{~kb}$. (B) 293 cells were transfected with PcDNA3.1-myc-Hiwi plasmid, and the cell lysates were subjected to western blotting using a Hiwi-directed antibody. (C) At $24 \mathrm{~h}$ after plating, primary mouse hepatocytes were incubated for $4 \mathrm{~h}$ with recombinant adenoviruses expressing Hiwi at a total multiplicity of infection of $10 \mathrm{pfu}$ per cell. The cells were then cultured for an additional $24 \mathrm{~h}$ in fresh medium, and the cell lysates were subjected to western blotting using a myc-directed antibody. The arrow indicates the Hiwi protein band. (D) SMMC7721 cells were transfected with pcDNA3.1-myc-Hiwi plasmid and were selected in $400 \mu \mathrm{g} / \mathrm{ml} \mathrm{G} 418$ for 2 weeks. The cell lines that stably express Hiwi at high (lanes 3 and 6 ) or low (lanes 1 and 4) levels were identified by western blot analysis using a Hiwi-directed antibody. The cell lines that do not express Hiwi were used as controls. Hiwi, piwi like RNA-mediated gene silencing 1.

$490 \mathrm{~nm}$ was measured with a microplate reader according to the manufacturer's protocol.

Analysis of cell proliferation by 5-ethynyl-2'-deoxyuridine $(E d U)$ assay. A total of $2 \times 10^{4}$ cells per well were seeded in 48-well plates and cultured overnight prior to infection with the adenovirus. At the indicated time, $150 \mu \mathrm{l}$ of $\mathrm{EdU}(50 \mu \mathrm{M}$; Guangzhou RiboBio Co., Ltd., Guangzhou, China) was added to each well. After $4 \mathrm{~h}$ of incubation at $37^{\circ} \mathrm{C}$, the cells were fixed and EdU incorporation was visualized using a Leica microscope (Leica Microsystems, Inc., Buffalo Grove, IL, USA).

Cell cycle analysis by flow cytometry. SMMC7721 cells were collected and fixed with ice-cold $70 \%$ ethanol at $4^{\circ} \mathrm{C}$ for $2 \mathrm{~h}$. Next, the cells were washed twice with PBS and incubated with DAPI in the presence of RNase A at $37^{\circ} \mathrm{C}$ for $30 \mathrm{~min}$ in the dark. The DNA contents were then measured using a flow cytometer (Applied Biosystems; Thermo Fisher Scientific, Inc.) and were analyzed by Modifit software (version 4.0; Verify Software House, Inc., Topsham, ME, USA) for the proportions of cells in the phases of the cell cycle.

Assessment of cell migration in culture. Two-dimensional cell migration was analyzed using a scratch wound assay. SMMC7721 cells were cultured in 6-well plate. The scratch was performed by using a $200 \mu$ l pipette tip to press firmly against the top of the tissue culture plate and swiftly make a vertical wound down through the cell monolayer. SMMC7721 cells were fixed with $70 \%$ ethanol and captured using a light microscope at $48 \mathrm{~h}$ after the scratch was made. The farthest distance that the cells migrated from the wound edge was measured by calculating the mean of three independent microscope fields in each of the three independent experiments.

Three-dimensional cell migration was determined using a Transwell migration assay as per the manufacturer's instructions (Corning Life Science, Corning, NY, USA). A total of 5,000 cells in serum-free DMEM were added into the top chamber. The bottom chamber contained $1 \%$ or $10 \%$ FBS in DMEM as a chemoattractant. After $24 \mathrm{~h}$, the cells that had not penetrated the filters were scraped from the upper surface. The membrane was fixed with formalin, and the cells that migrated to the bottom surface of the filter were stained with Giemsa at room temperature for 5-10 min (Beyotime Institute of Biotechnology) and counted using a light microscope (magnification, x200). An average of four randomly chosen fields were counted in each of the three independent experiments.

Effect of Hiwi on genes involved in the epithelial-mesenchymal transition (EMT) by reverse transcription-quantitative polymerase chain reaction ( $R T-q P C R)$ analysis. Total cellular RNA was extracted using TRIzol reagent (Takara Bio, Inc., Otsu, Japan) according to the manufacturer's instructions. Total RNA $(2 \mu \mathrm{g})$ was reverse transcribed at $50^{\circ} \mathrm{C}$ for $50 \mathrm{~min}$, and $70^{\circ} \mathrm{C}$ for $10 \mathrm{~min}$ using the PrimeScript RT reagent kit (Takara Bio, Inc.). qPCR was performed with Power SYBR Green PCR Master Mix (Applied Biosystems; Thermo Fisher 
Table I. Primer sequences for polymerase chain reaction.

\begin{tabular}{|c|c|c|c|}
\hline Gene & GeneBank accession number & Species & Primer sequence $\left(5^{\prime}-3^{\prime}\right)$ \\
\hline Hiwi & AF104260.2 & Human & \\
\hline Forward & - & - & GAAGCAGCCTGTCTTGGTCAGC \\
\hline Reverse & - & - & GAATCAAAGCTCAAACCCCAGTCTC \\
\hline E-cadherin & AB025106.1 & Human & \\
\hline Forward & - & - & GACACCAACGATAATCCT \\
\hline Reverse & - & - & TTTCAGTGTGGTGATTACGACGTTA \\
\hline N-cadherin & M34064.1 & Human & \\
\hline Forward & - & - & GGTGGAGGAGAAGAAGACCAG \\
\hline Reverse & - & - & GGCATCAGGCTCCACAGT \\
\hline$\alpha$-catenin & D13866.1 & Human & \\
\hline Forward & - & - & AGCGAAGATTGCGGAACAGGT \\
\hline Reverse & - & - & GCCTTGACCTTGCTGCAGATG \\
\hline Vimentin & NM_003380.3 & Human & \\
\hline Forward & - & - & GAGAACTTTGCCGTTGAAGC \\
\hline Reverse & - & - & TCCAGCAGCTTCCTGTAGGT \\
\hline GAPDH & AJ005371.1 & Human & \\
\hline Forward & - & - & TGTTCGTCATGGGTGTGAACC \\
\hline Reverse & - & - & GCAGTGATGGCATGGACTGTG \\
\hline E-cadherin & NM_009864.2 & Mouse & \\
\hline Forward & - & - & TCGGAAGACTCCCGATTCAAA \\
\hline Reverse & - & - & CGGACGAGGAAACTGGTCTC \\
\hline N-cadherin & NM_007664.4 & Mouse & \\
\hline Forward & - & - & CTCCAACGGGCATCTTCATTAT \\
\hline Reverse & - & - & CAAGTGAAACCGGGCTATCAG \\
\hline $\mathrm{Bcl} 2$ & NM_009741.5 & Mouse & \\
\hline Forward & - & - & ATGCCTTTGTGGAACTATATGGC \\
\hline Reverse & - & - & GGTATGCACCCAGAGTGATGC \\
\hline $\operatorname{Bax}$ & NM_007527.3 & Mouse & \\
\hline Forward & - & - & AGACAGGGGCCTTTTTGCTAC \\
\hline Reverse & - & - & AATTCGCCGGAGACACTCG \\
\hline P53 & AB021961.1 & Mouse & \\
\hline Forward & & & GTCACAGCACATGACGGAGG \\
\hline Reverse & & & TCTTCCAGATGCTCGGGATAC \\
\hline Mcl1 & NM_008562.3 & Mouse & \\
\hline Forward & & & TCCAAGGACTCGAAGCCTCT \\
\hline Reverse & & & CCAGTTTGTTACGCCATCTTTG \\
\hline GAPDH & AY618568.1 & Mouse & \\
\hline Forward & & & AGGTCGGTGTGAACGGATTTG \\
\hline Reverse & & & GGGGTCGTTGATGGCAACA \\
\hline
\end{tabular}

Hiwi, piwi like RNA-mediated gene silencing 1; Bcl-2, B-cell lymphoma 2; Bax, Bcl-associated X; p53, tumor protein p53; Mcl1, induced myeloid leukemia cell differentiation protein.

Scientific, Inc.) using a 7500 Real-Time PCR system. The thermal cycling conditions of the PCR were $94^{\circ} \mathrm{C}$ for $5 \mathrm{~min}$, followed by $22-35$ cycles for $20 \mathrm{sec}$ at $94^{\circ} \mathrm{C}, 20 \mathrm{sec}$ at $64^{\circ} \mathrm{C}$, $1 \mathrm{~min}$ at $72^{\circ} \mathrm{C}$, and the final extension at $72^{\circ} \mathrm{C}$ for $7 \mathrm{~min}$. The primer sequences used are listed in Table I. The relative quantities of mRNA were determined using the comparative cycle threshold method (21) and normalized against GAPDH mRNA.
Analysis of the effect of Hiwi or green fluorescent protein overexpression on apoptosis. Perifosine, an inhibitor of RAC serine/threonine-protein kinase (22) and doxorubicin were used to induce apoptosis in primary murine hepatocytes in vitro. A total of $5 \mu \mathrm{M}$ Perifosine and $2 \mu \mathrm{M}$ doxorubicin (DOX) were separately added to the primary murine hepatocytes $24 \mathrm{~h}$ following infection with recombinant adenovirus that express Hiwi or green fluorescent protein (GFP). Cell 
viability was evaluated at different time points by MTT assays.

Xenograft model to study tumor growth. Six-week-old male BALB/C nude mice $(n=18$, purchased from the experimental animal center of Nanjing medical University, Nanjing, China) were used to study the effect of Hiwi overexpression. They were allowed free access to drinking water and food at room temperature $\left(25^{\circ} \mathrm{C}\right)$ with an automatic $12 \mathrm{~h}$ light and $12 \mathrm{~h}$ dark cycle. All animal protocols and experimental procedures were approved by the Animal Care and Use Committee of Nanjing Medical University (Nanjing, China). SMMC7721 cells were transfected with pcDNA3.1-myc-Hiwi plasmid and selected with $400 \mu \mathrm{g} / \mathrm{ml} \mathrm{G} 418$ for 2 weeks, as aforementioned. A total of 9 colonies were selected. The colonies $(1,3,4,6)$ that stably expressed Hiwi were verified by western blot analysis (Fig. 1D). The colonies $(2,5,7-9)$ that did not express Hiwi were used as blank controls. Hiwi-expressing or blank control SMMC7721 cells ( $2 \times 10^{7}$ for each sample) were suspended in $0.2 \mathrm{ml}$ serum-free DMEM media and implanted into the flank of the nude mice mentioned above. After 70 days, the tumors were isolated, and the volumes were calculated from caliper measurements of tumor diameter.

Effects of Hiwi on genes associated with apoptosis and EMT in vivo. Adenoviruses expressing Hiwi or GFP $\left(5 \times 10^{9} \mathrm{pfu}\right)$ were injected into the tail vein of male BALB/c mice $(n=10)$. Anesthesia was achieved by the intraperitoneal administration of freshly prepared sodium pentobarbital $(60 \mathrm{mg} / \mathrm{kg}) 5$ days later. The mice were sacrificed by cervical dislocation, and the liver tissues were harvested. RT-qPCR was used to examine the expression of Hiwi, B-cell lymphoma 2 (Bcl-2), myeloid cell leukemia 1, Bcl-associated X, p53, E-cadherin and N-cadherin expression as aforementioned.

Statistical analysis. Data are expressed as the mean \pm standard deviation. Statistical significance was assessed using one-way analysis of variance and Scheffe test. In all statistical comparisons, $\mathrm{P}<0.05$ was considered to indicate a statistically significant difference.

\section{Results}

Effect of Hiwi overexpression on the proliferation and migration of liver cells. The growth curve of primary mouse hepatocytes that were infected with Hiwi-expressing adenovirus did not differ significantly from the control cells (Fig. 2A). Next, the functional role of Hiwi in cell division and cell cycle of liver cells was analyzed. As indicated in Fig. 2B, overexpression of Hiwi did not alter the percentage of SMMC7721 cells in $G_{1}, S$ and $G_{2} / M$ phases. No significant difference was observed between the Hiwi-overexpressing and control SMMC7721 cells in the EdU incorporation assays (Fig. 2C). These results indicate that overexpression of Hiwi did not affect liver cell proliferation.

Subsequently, the effect of Hiwi on the invasion of liver cells was examined. As indicated by the scratch migration assay, the average distance that SMMC7721 cells overexpressing Hiwi migrated at $48 \mathrm{~h}$ after the cell scratch did not differ significantly from the control cells (Fig. 3A). The
A

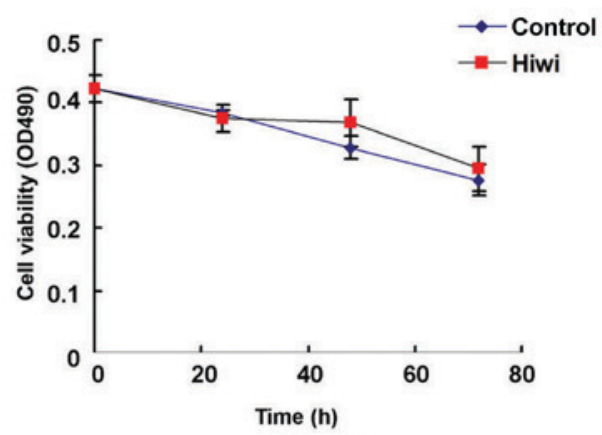

B

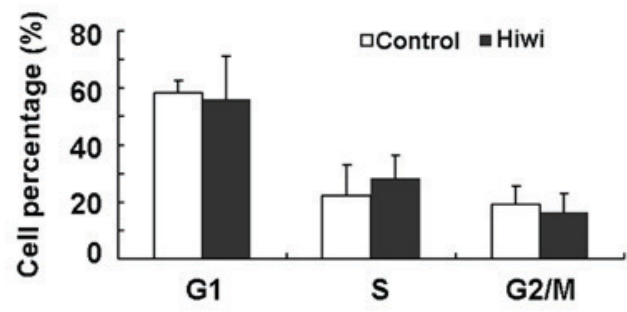

C

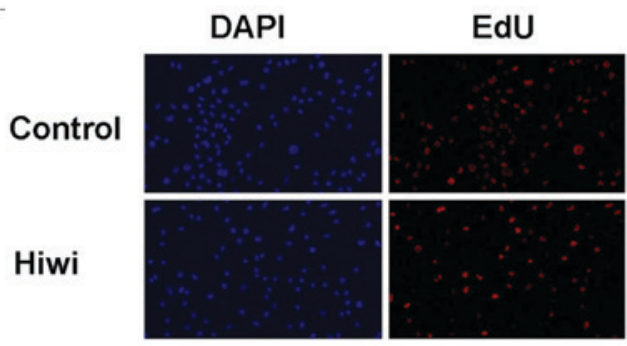

Figure 2. Effect of Hiwi overexpression on liver cell proliferation. (A) Primary mouse hepatocytes were infected with Hiwi-expressing or control adenovirus $24 \mathrm{~h}$ following plating. Cell viability was assessed by an MTT assay $(\mathrm{n}=3)$ at the indicated times. (B) SMMC7721 cells were incubated with recombinant adenoviruses for $48 \mathrm{~h}$. The cell cycle was analyzed by flow cytometry $(\mathrm{n}=3)$. (C) The proliferative rate of Hiwi-overexpressing and control SMMC7721 cells was assessed by EdU incorporation assay (magnification, x200). Hiwi, piwi like RNA-mediated gene silencing 1; OD, optical density.

effect of Hiwi expression on SMMC7721 cell migration was also assessed by Transwell assay using a modified Boyden chamber. The fraction of SMMC7721 cells overexpressing Hiwi that migrated through a gelatin-coated membrane in response to $1 \%$ or $10 \%$ FBS did not differ significantly from the control cells (Fig. 3B). These data indicated that overexpression of Hiwi did not affect the migration of liver cells.

To assess the effect of Hiwi on genes involved in EMT, levels of $\alpha$-catenin, E-cadherin, $\mathrm{N}$-cadherin and vimentin mRNA were measured by RT-qPCR. Consistently, levels of $\alpha$-catenin, E-cadherin, $\mathrm{N}$-cadherin and vimentin mRNA did not differ significantly between Hiwi-overexpressing cells and control cells (Fig. 4).

Effect of Hiwi on drug-induced apoptosis in vitro. Oncoproteins, such as Bcl-2, contribute to neoplastic cell growth primarily by promoting cell survival via interfering with apoptosis (23). Therefore, it was hypothesized that Hiwi might promote tumor growth by inhibiting apoptosis. Mouse primary hepatocytes 
A
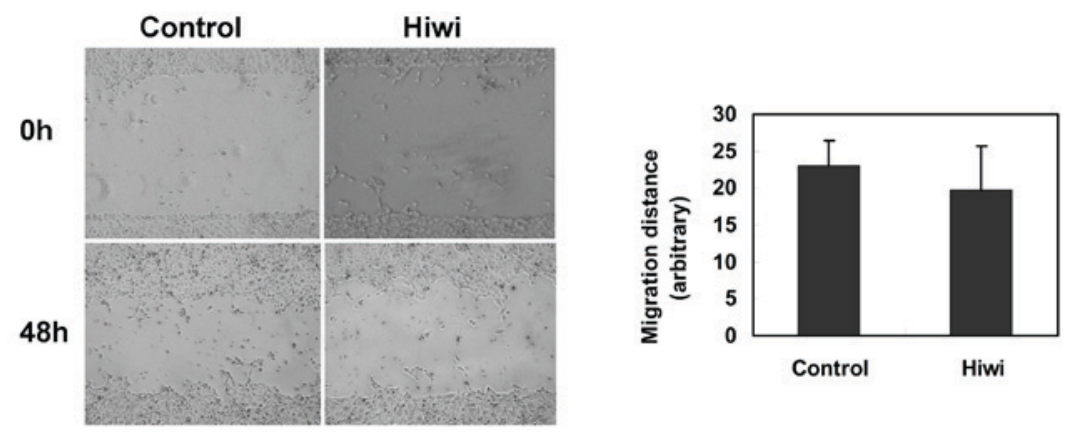

B
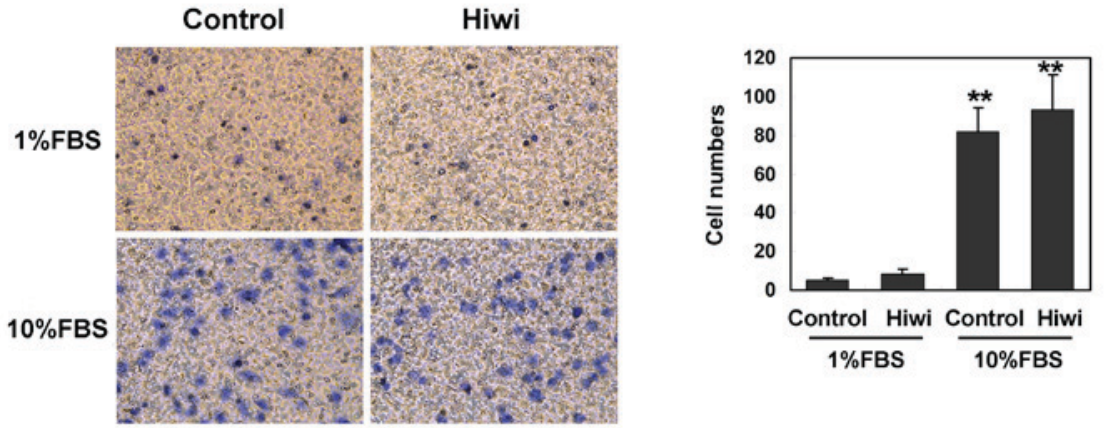

Figure 3. Effect of Hiwi overexpression on the migration of liver cells. (A) SMMC7721 cells were incubated with recombinant adenoviruses expressing Hiwi at a total multiplicity of infection of 20 pfu per cell. Cell migration was observed $48 \mathrm{~h}$ after the scratch was made (magnification, $\mathrm{x} 100 ; \mathrm{n}=3$ ). (B) The migration of SMMC7721 cells was assessed in a Transwell migration assay using a modified Boyden chamber in response to 1 or 10\% FBS (magnification, x200, n=3). ${ }^{* *} \mathrm{P}<0.05$ vs. the $1 \%$ FBS group. Data are presented as the mean \pm standard deviation from three independent experiments. FBS, fetal bovine serum; Hiwi, piwi like RNA-mediated gene silencing 1.

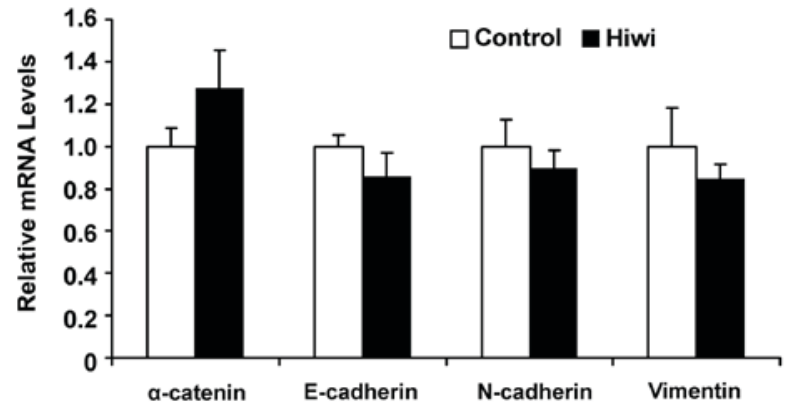

Figure 4. Effect of Hiwi on genes involved in the epithelial-mesenchymal transition. Primary mouse hepatocytes were incubated with Hiwi-expressing or control adenovirus for $24 \mathrm{~h}$ after plating. The mRNA levels of the indicated genes were analyzed by reverse transcription-quantitative polymerase chain reaction. Data are presented as the mean \pm standard deviation from three experiments. Hiwi, piwi like RNA-mediated gene silencing 1 .

were treated with perifosine and subsequently a significant reduction in cell viability was observed (Fig. 5). However, the overexpression of Hiwi did not enhance the survival of perifosine-treated cells (Fig. 5). DOX is a widely used anticancer drug that induces apoptosis (24). Overexpression of Hiwi had no detectable effect on DOX-induced hepatotoxicity and apoptosis (Fig. 5). These results indicated that overexpression of Hiwi did not inhibit apoptosis.

Effect of Hiwi overexpression on the growth of HCC xenografts. Although exogenous expression of Hiwi did not affect liver cell growth in vitro, the growth of Hiwi-overexpressing $\mathrm{HCC}$ cells was examined in vivo. Hiwi-expressing SMMC7721 cells were

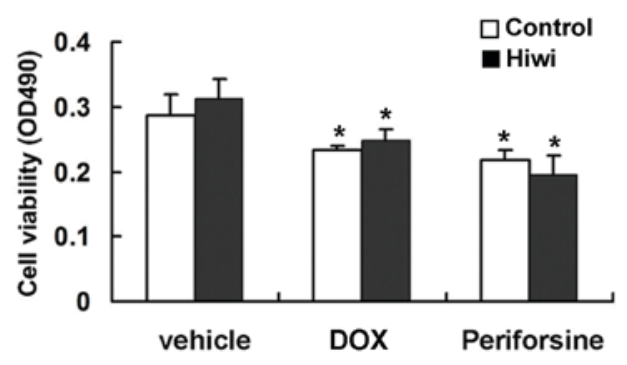

Figure 5. Effect of Hiwi overexpression on the apoptosis of liver cells Primary mouse hepatocytes were infected with Hiwi-expressing or control adenovirus $24 \mathrm{~h}$ after plating. Then cells were treated with $5 \mu \mathrm{M}$ perifosine or $2 \mu \mathrm{M}$ DOX. After $24 \mathrm{~h}$, cell viability was assessed by MTT assay $(\mathrm{n}=3)$. ${ }^{*} \mathrm{P}<0.05$ vs. the vehicle. Data are presented as the mean \pm standard deviation from three experiments. Hiwi, piwi like RNA-mediated gene silencing 1; DOX, doxorubicin; OD, optical density.

implanted into the flank of 6-weeks-old BALB/c nude mice. After 70 days, tumor volume was measured. Consistently, the mean size of tumors derived from Hiwi-expressing cells did not differ significantly from the tumors that derived from control cells (Fig. 6). These results indicated that overexpression of Hiwi did not alter tumor growth in vivo.

Role of Hiwi overexpression in altering the expression of genes that are involved in EMT or apoptosis. The mice were injected with adenovirus expressing Hiwi or GFP $\left(5 \times 10^{9} \mathrm{pfu}\right)$ in the tail vein. After 5 days, Hiwi was detected in hepatocytes via RT-qPCR and western blot analysis. Expression of genes that are involved in EMT or apoptosis expressed by these hepatocytes did not differ significantly between mice that were injected with the Hiwi-expressing vector or the control adenoviral vector (Fig. 7). 


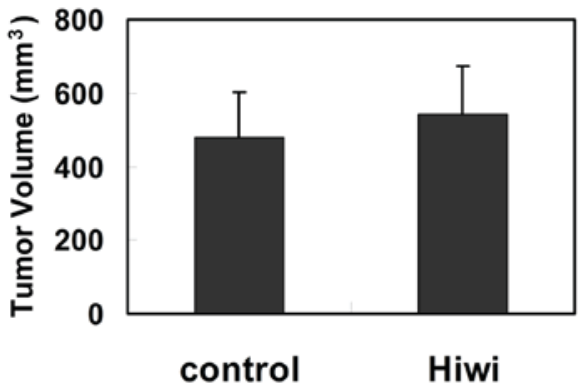

Figure 6. Effect of Hiwi overexpression on tumor growth in vivo. An equal number $\left(2 \times 10^{7}\right)$ of Hiwi-expressing (no. 3 in Fig 1D) stable cells or controls were injected subcutaneously into the flank of nude mice. At 70 days later, the tumors derived from parental cells were isolated, and the tumor volume was calculated. The diameter of the tumors were measured using a caliper. Colonies 6, 1 and 4 in Fig 1D were also tested and similar results were observed. Data are presented as the mean \pm standard deviation ( $\mathrm{n}=8$ in control group, $\mathrm{n}=10$ in Hiwi group). Hiwi, piwi like RNA-mediated gene silencing 1 .

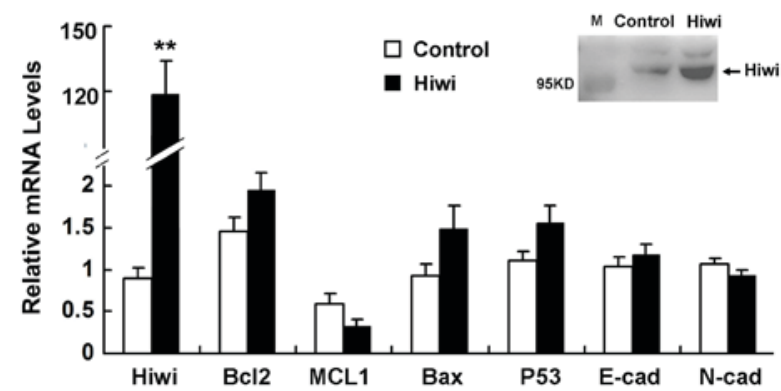

Figure 7. Effect of Hiwi overexpression on hepatocyte gene expression in vivo. Adenovirus expressing Hiwi or green fluorescent protein $\left(5 \times 10^{9} \mathrm{pfu}\right)$ were injected via the mouse tail vein. The livers were harvested 5 days after injection. The mRNA levels of Hiwi, Bcl2, MCL1 and Bax were analyzed by reverse transcription-quantitative polymerase chain reaction. ${ }^{* *} \mathrm{P}<0.01$ vs. the control. Insert: The livers were harvested 5 days after adenovirus injection. Hiwi expression was detected by western blotting using a myc-directed antibody. M, marker; Hiwi, piwi like RNA-mediated gene silencing 1; Bcl-2, B-cell lymphoma 2; Bax, Bcl-associated X; p53, tumor protein p53; Mcl1, induced myeloid leukemia cell differentiation protein; E-cad, E-cadherin.

\section{Discussion}

Hiwi has been suggested to have a role in several human malignant tumors $(2,3,5,7)$, and increased expression of the Hiwi gene has been demonstrated in seminoma cell hyperplasia (2), esophageal squamous cell carcinoma (3), gastric carcinoma (5), and pancreas adenocarcinoma (4). In the majority of cases, increased expression of Hiwi was detected in tumors and found to be associated with poorer patient outcomes $(2-8,17,18)$. These prior studies indicated that Hiwi expression might be a useful clinical marker of germ cell malignancies and solid tumors of epithelial or mesenchymal origin.

Previous studies revealed that significant decreases in Hiwi expression were observed in renal cell carcinoma, and Hiwi expression was found to be inversely associated with overall survival $(25,26)$. Functional analysis of Hiwi protein has also generated conflicting results. Although overexpression of Hiwi has been demonstrated to promote the growth of breast or cervical tumors $(9,10)$, in acute or chronic myeloid leukemia cell lines Hiwi proteins may suppress proliferation $(14,15)$. These findings indicate that the function of Hiwi differs in different cellular contexts, and the biological function of Hiwi remains poorly understood.

Since the downregulation of Hiwi suppressed proliferation and invasion of HCC cells $(18,19)$, we hypothesized that the overexpression of Hiwi may contribute to the development and progression of HCC. However, overexpression of Hiwi in SMMC7721 HCC cell lines, primary mouse hepatocytes, xenografts and an adenovirus-mediated mouse hepatic gene-expression model did not alter the proliferation, migration or apoptosis of liver cells in vitro or in vivo. Although Hiwi expression was elevated in HCC $(17,18)$, it did not appear to function as an oncoprotein. The RNAi-mediated downregulation of Hiwi was previously revealed to suppress the proliferation and invasion of HCC cell lines (18). Therefore, we hypothesize that Hiwi may be necessary but not sufficient for tumor genesis of liver cells.

Similar results were previously obtained in gastric cancer cells. Overexpression of Hiwi in AGS cells did not alter their proliferative rate, whereas suppression of Hiwi expression using antisense RNAs or RNAi inhibited cell growth and induced cell cycle arrest (5). One possible explanation for this discrepancy would be that, in certain types of tumors, other cellular factors might be required to interact with Hiwi to promote tumorigenesis. The existence of additional signaling pathways that counteract the function of Hiwi in these tumors cannot be ruled out. Additionally, the findings of the present study do not necessarily reflect the role of Hiwi in humans in vivo, and other unknown mechanisms may well affect tumor growth in humans.

In summary, the findings of the present study indicate that although expression of Hiwi is associated with the development and progression of HCC, it does not act as an oncogene in liver cancer cells. To characterize the contribution of Hiwi to the progression of $\mathrm{HCC}$ in humans further, other factors or pathways that interact with Hiwi require elucidation.

\section{Acknowledgements}

Not applicable.

\section{Funding}

The present study was supported by the National Natural Science Foundation of China (grant no. 81101800), the 12th Six Talents Peak Project of Jiangsu Province (grant no. 2015-WSN-028), the Priority Academic Program Development of Jiangsu Higher Education Institutions (PAPD) (grant no. JX10231801) and the Research Project of Chinese Medical Association and Chinese High Education Association (grant no. 2016B-KC019).

\section{Availability of data and materials}

The datasets analyzed during the current study are available from the corresponding author on reasonable request.

\section{Authors' contributions}

CXS and HaL performed the cloning and transfection of plasmids, and generated SMMC7721 cells stably expressing Hiwi. HuL and HaL performed the apoptosis assays and generated xenograft model. HHZ and HMS assisted in the flow cytometry 
analysis. MDS, JLC and SFX studied the expression of genes and analyzed the data. HaL and JXJ designed the study and wrote the manuscript. All authors read and approved the final manuscript.

\section{Ethics approval and consent to participate}

All animal protocols and experimental procedures were approved by the Animal Care and Use Committee of Nanjing Medical University (Nanjing, China).

\section{Consent for publication}

Not applicable.

\section{Competing interests}

The authors declare that they have no competing interest.

\section{References}

1. Suzuki R, Honda S and Kirino Y: PIWI expression and function in cancer. Front Genet 3: 204, 2012.

2. Qiao D, Zeeman AM, Deng W, Looijenga LH and Lin H: Molecular characterization of hiwi, a human member of the piwi gene family whose overexpression is correlated to seminomas. Oncogene 21: 3988-3999, 2002.

3. He W, Wang Z, Wang Q, Fan Q, Shou C, Wang J, Giercksky KE, Nesland JM and Suo Z: Expression of HIWI in human esophageal squamous cell carcinoma is significantly associated with poorer prognosis. BMC Cancer 9: 426, 2009.

4. Grochola LF, Greither T, Taubert H, Möller P, Knippschild U, Udelnow A, Henne-Bruns D and Würl P: The stem cell-associated Hiwi gene in human adenocarcinoma of the pancreas: Expression and risk of tumour-related death. Br J Cancer 99: 1083-1088, 2008.

5. Liu X, Sun Y, Guo J, Ma H, Li J, Dong B, Jin G, Zhang J, Wu J, Meng L and Shou C: Expression of hiwi gene in human gastric cancer was associated with proliferation of cancer cells. Int J Cancer 118: 1922-1929, 2006.

6. Raeisossadati R, Abbaszadegan MR, Moghbeli M, Tavassoli A, Kihara $\mathrm{AH}$ and Forghanifard MM: Aberrant expression of DPPA2 and HIWI genes in colorectal cancer and their impacts on poor prognosis. Tumour Biol 35: 5299-5305, 2014.

7. Taubert H, Greither T, Kaushal D, Würl P, Bache M, Bartel F, Kehlen A, Lautenschläger C, Harris L, Kraemer K, et al: Expression of the stem cell self-renewal gene Hiwi and risk of tumour-related death in patients with soft-tissue sarcoma. Oncogene 26: 1098-1100, 2007.

8. Chen Z, Che Q, He X, Wang F, Wang H, Zhu M, Sun J and Wan X: Stem cell protein Piwill endowed endometrial cancer cells with stem-like properties via inducing epithelial-mesenchymal transition. BMC Cancer 15: 811, 2015.

9. Wang DW, Wang ZH, Wang LL, Song Y and Zhang GZ: Overexpression of hiwi promotes growth of human breast cancer cells. Asian Pac J Cancer Prev 15: 7553-7558, 2014.

10. Liu W, Gao Q, Chen K, Xue X, Li M, Chen Q, Zhu G and Gao Y: Hiwi facilitates chemoresistance as a cancer stem cell marker in cervical cancer. Oncol Rep 32: 1853-1860, 2014.
11. Siddiqi S, Terry M and Matushansky I: Hiwi mediated tumorigenesis is associated with DNA hypermethylation. PLoS One 7: e33711, 2012.

12. Wang X, Tong X, Gao H, Yan X, Xu X, Sun S, Wang Q and Wang J: Silencing HIWI suppresses the growth, invasion and migration of glioma cells. Int J Oncol 45: 2385-2392, 2014.

13. Liang D, Fang Z, Dong M, Liang C, Xing C, Zhao J and Yang Y: Effect of RNA interference-related HiWi gene expression on the proliferation and apoptosis of lung cancer stem cells. Oncol Lett 4: 146-150, 2012.

14. Sharma AK, Nelson MC, Brandt JE, Wessman M, Mahmud N, Weller KP and Hoffman R: Human CD34(+) stem cells express the hiwi gene, a human homologue of the Drosophila gene piwi. Blood 97: 426-434, 2001

15. Wang Y, Jiang Y, Ma N, Sang B, Hu X, Cong X and Liu Z: Overexpression of Hiwi inhibits the growth and migration of chronic myeloid leukemia cells. Cell Biochem Biophys 73: 117-124, 2015.

16. Kao JH and Chen DS: Changing disease burden of hepatocellular carcinoma in the Far East and Southeast Asia. Liver Int 25: 696-703, 2005.

17. Jiang J, Zhang H, Tang Q, Hao B and Shi R: Expression of HIWI in human hepatocellular carcinoma. Cell Biochem Biophys 61: 53-58, 2011.

18. Zhao YM, Zhou JM, Wang LR, He HW, Wang XL, Tao ZH, Sun HC, Wu WZ, Fan J, Tang ZY and Wang L: HIWI is associated with prognosis in patients with hepatocellular carcinoma after curative resection. Cancer 118: 2708-2717, 2012.

19. Xie Y, Yang Y, Ji D, Zhang D, Yao X and Zhang X: Hiwi downregulation, mediated by shRNA, reduces the proliferation and migration of human hepatocellular carcinoma cells. Mol Med Rep 11: 1455-1461, 2015.

20. Webber C, Gospodarowicz M, Sobin LH, Wittekind C, Greene FL, Mason MD, Compton C, Brierley J and Groome PA: Improving the TNM classification: Findings from a 10 -year continuous literature review. Int J Cancer 135: 371-378, 2014.

21. Livak KJ and Schmittgen TD: Analysis of relative gene expression data using real-time quantitative PCR and the 2(-Delta Delta C(T)) method. Methods 25: 402-408, 2001.

22. Fei HR, Chen G, Wang JM and Wang FZ: Perifosine induces cell cycle arrest and apoptosis in human hepatocellular carcinoma cell lines by blockade of Akt phosphorylation. Cytotechnology 62: 449-460, 2010.

23. Miyashita T and Reed JC: Bcl-2 oncoprotein blocks chemotherapy-induced apoptosis in a human leukemia cell line. Blood 81: 151-157, 1993.

24. Mizutani H, Tada-Oikawa S, Hiraku Y, Kojima M and Kawanishi S: Mechanism of apoptosis induced by doxorubicin through the generation of hydrogen peroxide. Life Sci 76: $1439-1453,2005$.

25. Al-Janabi O, Wach S, Nolte E, Weigelt K, Rau TT, Stöhr C, Legal W, Schick S, Greither T, Hartmann A, et al: Piwi-like 1 and 4 gene transcript levels are associated with clinicopathological parameters in renal cell carcinomas. Biochim Biophys Acta 1842: 686-690, 2014.

26. IlievR,Stanik M,Fedorko M,Poprach A,Vychytilova-FaltejskovaP, Slaba K, Svoboda M, Fabian P, Pacik D, Dolezel J and Slaby O: Decreased expression levels of PIWIL1, PIWIL2, and PIWIL4 are associated with worse survival in renal cell carcinoma patients. Onco Targets Ther 9: 217-222, 2016.

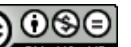

This work is licensed under a Creative Commons Attribution-NonCommercial-NoDerivatives 4.0 International (CC BY-NC-ND 4.0) License. 